\title{
CRITICAL ANALYSIS OF VISUAL OUTCOME IN CLEAR CORNEAL MANUAL SMALL INCISION CATARACT SURGERY AT EYE CAMPS
}

\author{
Sudhir Sudhakar Pendke1, Sanchit Satish Bhalgat ${ }^{2}$
}

${ }^{1}$ Associate Professor, Department of Ophthalmology, Indira Gandhi Government Medical College, Nagpur, Maharashtra University of Health Sciences, Nasik, India.

${ }^{2}$ M.B.B.S., Diploma in Ophthalmology, Indira Gandhi Government Medical College, Nagpur, Maharashtra University of Health Sciences, Nasik, India.

\section{ABSTRACT}

The study aims at analysis of visual outcomes in clear corneal cataract surgery as per WHO guidelines at eye camps. The need to maximise visual outcome after cataract surgery is obvious and routine monitoring of visual outcome can be a mechanism to achieve this. Clear Corneal Manual Small Incision Cataract Surgery was the procedure performed in this study and the outcomes recorded and analysed.

\section{MATERIALS}

This camp-based prospective study included 483 eyes of 483 patients with senile cataract without comorbid ocular or systemic conditions, who gave consent. Manual SICS with Clear Corneal Incision was performed by experienced ophthalmic Surgeon. Patients were followed up on 1, 7, 15 days and 1, 3, 6,12 months evaluated for results.

\section{RESULTS}

Manual small incision cataract surgery with clear corneal tunnel was the technique. From 483 patients, 458 came for follow-up postoperatively. From 458 cases, good visual outcome seen in 396 (86.43\%) patients, which fairly meets the guidelines by WHO. Study indicates that intraoperative complications (8.25\%) are the major cause affecting the final visual outcome. Intraoperative complications occurred in $44(9.8 \%)$ patients, which is below maximum limit of $10 \%$ as per guidelines given by WHO. Posterior Capsule Rent occurred in 16 (3.64\%) patients is common intraoperative complication followed by vitreous loss 13 (3.32\%). Rate of both complications is below the maximum limit of $5 \%$ as per guidelines given by WHO. Similarly, post-operative complications including Surgically Induced Astigmatism. Cystoid Macular Oedema, Retinal Detachment and Endophthalmitis were below 5\%.

\section{CONCLUSION}

Visual outcome of clear corneal cataract surgery at the eye camps meet the guidelines of WHO. Intraoperative complications are important causes of low visual outcome in our study. This study advocates improvement in visual outcome lies in reducing incidence of intraoperative and postoperative complications and management of them with good quality of instruments and modern techniques. Routine monitoring of visual outcome of cataract surgery at every hospital will go in a long way to improve both quantity and quality of surgery and thus reduce the substantial amount of burden of blindness on our country.

\section{KEYWORDS}

Clear Cornea SICS, WHO Guidelines, Visual Outcome, Eye Camps.

HOW TO CITE THIS ARTICLE: Pendke SS, Bhalgat SS. Critical analysis of visual outcome in clear corneal manual small incision cataract surgery at eye camps. J. Evolution Med. Dent. Sci. 2016;5(41):2535-2538, DOI: 10.14260/jemds/2016/592

\section{INTRODUCTION}

Cataract is the world's leading cause of blindness. In India Cataract accounts for $62.6 \%$ of total blindness. Recognizing this, the main emphasis of the National Program for Control of Blindness (NPCB) in India was on cataract blindness control. Several studies have indicated that the long term visual outcome of cataract surgery is often far from optimal. The need to maximise visual outcome after cataract surgery is obvious and routine monitoring of visual outcome can be a mechanism to achieve this. Clear Corneal Manual Small Incision Cataract Surgery was the procedure performed in this study and the outcomes recorded and analysed.

Financial or Other, Competing Interest: None.

Submission 07-04-2016, Peer Review 02-05-2016,

Acceptance 07-05-2016, Published 23-05-2016.

Corresponding Author:

Dr. Sudhir Sudhakar Pendke,

17, Shastri Layout,

Subhash Nagar

Nagpur-440022.

E-mail: sudhirpendke@rediffmail.com

DOI: 10.14260/jemds/2016/592
Our study evaluates visual outcome of the above procedure by recording visual acuity, which is arguably the best indicator of successful surgery.

Our study aims at evaluation and analysis of visual outcome of clear corneal manual small incision cataract surgery, critical analysis of various causes of poor vision postoperatively and recommendations based upon study findings.

\section{MATERIALS AND METHODS}

Visual outcome is crucial both for the patients and for the eye care provider. Good outcomes are essential and poor outcomes experienced by patients following surgery will affect the demand for cataract surgery by the community. In this study, attempt was made to evaluate visual outcome of clear corneal cataract surgery and understand the causes of low visual outcome. This prospective longitudinal analytical study was conducted at Eye Camps.

\section{Inclusion Criteria}

All senile cataract patients above the 50 years of age selected for surgery. 


\section{Exclusion Criteria}

Complicated cataract, traumatic cataract or cataracts with any posterior segment pathology.

\section{Ethical Clearance}

After approval from ethical committee, an informed consent was obtained from every patient. Thorough standard preoperative evaluation was done which included slit lamp biomicroscopy, fundus examination, calculation of IOL power.

Informed consent was taken from all the patients before surgery.

Cataract surgery was done under peribulbar anaesthesia and under all aseptic precautions. Cataract surgery was performed by a single experienced ophthalmologist. Manual small incision cataract surgery with clear corneal tunnel was the technique performed.

\section{Follow-up}

Patients were followed up on first postoperative day and discharged and followed up on $1^{\text {st }} 4^{\text {th }}$ and $8^{\text {th }}$ week. Early postoperative complications were recorded and managed. Complete ophthalmological evaluation conducted at each visit including visual acuity, slit lamp biomicroscopy, direct and indirect ophthalmoscopy. Spectacle correction given where needed. Best corrected visual acuity recorded at $8^{\text {th }}$ week, analysed irrespective of type of surgery done and categorized according to guidelines given by WHO (World Health Organisation).

WHO Guidelines for Postoperative Visual Outcome

\begin{tabular}{|c|c|c|}
\hline Visual Outcome & $\begin{array}{c}\text { With Available } \\
\text { Correction }\end{array}$ & $\begin{array}{c}\text { With Best } \\
\text { Correction }\end{array}$ \\
\hline Good 6/6-6/18 & $>80 \%$ & $>90 \%$ \\
\hline $\begin{array}{c}\text { Borderline } \\
<6 / 18-6 / 60\end{array}$ & $<15 \%$ & $<5 \%$ \\
\hline Poor $<6 / 60$ & $<5 \%$ & $<5 \%$ \\
\hline
\end{tabular}

*Available Correction: Functioning visual acuity correction.

\begin{tabular}{|c|c|c|c|c|}
\hline $\begin{array}{c}\text { Age Group } \\
\text { (Years) }\end{array}$ & Male & Female & Total & $\begin{array}{c}\text { Percentage } \\
\text { (\%) }\end{array}$ \\
\hline $50-60$ & 61 & 74 & 135 & 27.91 \\
\hline $61-70$ & 117 & 136 & 253 & 52.43 \\
\hline $71-80$ & 38 & 47 & 85 & 17.60 \\
\hline$\geq 81$ & 4 & 6 & 10 & 2.06 \\
\hline Total Table 1: Age \& Sex Distribution \\
\hline \multicolumn{6}{|c}{} \\
\hline
\end{tabular}

*Best Correction: With pinhole or adequate spectacle

\begin{tabular}{|c|c|c|}
\hline Type of Cataract & $\begin{array}{c}\text { Number of } \\
\text { Cases }\end{array}$ & Percentage (\%) \\
\hline Nuclear Sclerosis & 168 & 34.78 \\
\hline Cortical & 71 & 14.69 \\
\hline $\begin{array}{c}\text { Posterior } \\
\text { Subcapsular }\end{array}$ & 104 & 21.53 \\
\hline Posterior Polar & 22 & 4.55 \\
\hline Mature & 114 & 23.6 \\
\hline Hypermature & 4 & 0.83 \\
\hline Total Table 2: Type of Cataract \\
\hline \multicolumn{2}{|c|}{} \\
\hline
\end{tabular}

\begin{tabular}{|c|c|c|}
\hline Visual Acuity & Number of Cases & Percentage (\%) \\
\hline$\leq 3 / 60$ & 281 & 58.18 \\
\hline $4-60-6 / 60$ & 180 & 37.27 \\
\hline$>6 / 60$ & 22 & 4.55 \\
\hline Total & 483 & 100 \\
\hline \multicolumn{2}{|c|}{ Table 3: Preoperative Visual Acuity } \\
\hline
\end{tabular}

\begin{tabular}{|c|c|c|}
\hline Postoperative BCVA & $\begin{array}{c}\text { Number of } \\
\text { Cases }\end{array}$ & $\begin{array}{c}\text { Percentage } \\
(\%)\end{array}$ \\
\hline Good (6/6-6/18) & 396 & 86.46 \\
\hline $\begin{array}{c}\text { Borderline }(6 / 12- \\
6 / 60)\end{array}$ & 54 & 11.79 \\
\hline Poor $(<6 / 60)$ & 8 & 1.75 \\
\hline Total & 458 & 100 \\
\hline \multicolumn{3}{|c|}{ Table 4: Postoperative BCVA at 8 Weeks } \\
\hline
\end{tabular}

\begin{tabular}{|c|c|c|c|}
\hline Causes & $\begin{array}{c}\text { Borderline } \\
\text { Outcome }\end{array}$ & $\begin{array}{c}\text { Poor } \\
\text { Outcome }\end{array}$ & Total \\
\hline $\begin{array}{c}\text { Intraoperative } \\
\text { Complications }\end{array}$ & 34 & 5 & $\begin{array}{c}39 \\
(8.51 \%)\end{array}$ \\
\hline $\begin{array}{c}\text { Retained Lens } \\
\text { Material }\end{array}$ & 19 & 3 & $22(4.8 \%)$ \\
\hline Others & - & 1 & $1(0.21 \%)$ \\
\hline Total & 53 & 9 & $\begin{array}{c}62 \\
(13.53 \%)\end{array}$ \\
\hline \multicolumn{4}{|r|}{ Table 5: Causes of Borderline \& Poor Outcome } \\
\hline
\end{tabular}

\begin{tabular}{|c|c|c|}
\hline $\begin{array}{l}\text { Intraoperative } \\
\text { Complications }\end{array}$ & $\begin{array}{l}\text { Number of } \\
\text { Cases }\end{array}$ & $\begin{array}{c}\text { Percentage } \\
(\%)\end{array}$ \\
\hline PC Rent & 16 & $3.49 \%$ \\
\hline PC RENT + Vitreous Loss & 13 & $2.83 \%$ \\
\hline Tunnel Complication & 5 & $1.1 \%$ \\
\hline Zonular Dehiscence & 7 & $1.52 \%$ \\
\hline Descemet's Detachment & 1 & $0.22 \%$ \\
\hline Iridodialysis & 2 & $0.44 \%$ \\
\hline Total & 44 & $9.6 \%$ \\
\hline
\end{tabular}

\begin{tabular}{|c|c|c|c|c|c|c|c|}
\hline \multirow{2}{*}{$\begin{array}{c}\text { Visual } \\
\text { Outcome }\end{array}$} & \multicolumn{6}{|c|}{ Intraoperative Complications } & \multirow[b]{2}{*}{ Total } \\
\hline & $\begin{array}{c}\text { PC } \\
\text { Rent }\end{array}$ & $\begin{array}{c}\text { PC Rent } \\
+ \text { Vitreous Loss }\end{array}$ & $\begin{array}{l}\text { Zonular } \\
\text { Dialysis }\end{array}$ & $\begin{array}{c}\text { Tunnel } \\
\text { Complications }\end{array}$ & Iridodialysis & $\begin{array}{l}\text { Descemet's } \\
\text { Detachment }\end{array}$ & \\
\hline Good & 1 & 1 & 0 & 0 & 2 & 1 & 5 \\
\hline Borderline & 15 & 9 & 7 & 3 & 0 & 0 & 34 \\
\hline Poor & 0 & 3 & 0 & 2 & 0 & 0 & 5 \\
\hline Total & 16 & 13 & 7 & 5 & 2 & 1 & 44 \\
\hline
\end{tabular}




\begin{tabular}{|c|c|c|}
\hline Postoperative Complication & Number of Cases & Percentage \\
\hline Astigmatism & 10 & $2.2 \%$ \\
\hline Cystoid Macular Oedema & 4 & $0.8 \%$ \\
\hline Retinal Detachment & 2 & $0.4 \%$ \\
\hline Endophthalmitis & 3 & $0.6 \%$ \\
\hline Total Table 8: Analysis of Total Postoperative Complications & $\mathbf{4 . 1 \%}$ \\
\hline
\end{tabular}

\begin{tabular}{|c|c|c|c|c|}
\hline Intraoperative Complications & Astigmatism & Cystoid Macular Oedema & Retinal Detachment & Endophthalmitis \\
\hline None & 0 & 0 & 0 & 0 \\
\hline PC Rent & 0 & 1 & 0 & 0 \\
\hline PC Rent + Vitreous Loss & 0 & 0 & 4 & 3 \\
\hline Tunnel Complication & 4 & 0 & 0 & 0 \\
\hline Zonular Dehiscence & 6 & 1 & 0 & 0 \\
\hline Descemet's Detachment & 0 & 0 & 0 & 0 \\
\hline Iridodialysis Table 9: Association of Intraoperative and Postoperative Complications \\
\hline Total
\end{tabular}

\begin{tabular}{|c|c|c|}
\hline Causes & $\begin{array}{l}\text { Borderline } \\
\text { Outcome }\end{array}$ & $\begin{array}{c}\text { Poor } \\
\text { Outcome }\end{array}$ \\
\hline Astigmatism & 10 & 0 \\
\hline $\begin{array}{l}\text { Cystoid Macular } \\
\text { Oedema }\end{array}$ & 4 & 0 \\
\hline Retinal Detachment & 0 & 2 \\
\hline Endophthalmitis & 0 & 3 \\
\hline Total & 14 & 5 \\
\hline \multicolumn{3}{|c|}{$\begin{array}{c}\text { Table 10: Post-operative Complications } \\
\text { Causing Borderline \& Poor Outcome }\end{array}$} \\
\hline
\end{tabular}

\section{RESULTS}

Out of 483 patients, 263 (54\%) were females and 220 (46\%) were males. Patients in the 61 to 70 years' age group were maximum accounting for 253 cases. Mean age group being 64.9 years (Table 1 ).

In 483 patients, nuclear sclerosis was common and seen in $168(34.78 \%)$ of patients (Table 2).

Preoperative visual acuity was classified into three groups. Majority of the patients had visual acuity less than $3 / 60$ (58.18\%) (Table 3).

Out of 483 patients, 458 came for follow-up at 8 weeks following surgery. Out of 458 cases, good visual outcome was seen in $396(86.46 \%)$ patients which fairly meets the guidelines given by WHO (Table 4). Data of patients with borderline and poor outcome was studied and it is found that intraoperative complications $(8.51 \%)$ are the major cause affecting the final visual outcome (Table 5).

Intraoperative complications occurred in total $44(9.6 \%)$ patients, which shorts fall of the maximum limit of $10 \%$ as per guidelines given by WHO (Table 6). So intraoperative complications are responsible for low visual outcome in 39 (8.51\%) patients. PC rent (Posterior Capsule Rent) occurred in $16(3.49 \%)$ patients is most common intraoperative complication followed by PC rent with vitreous loss 13 $(2.83 \%)$. Rate of both complications is well below the maximum limit of $5 \%$ as per guidelines given by WHO. Nuclear sclerosis is significantly associated with PC rent with or without vitreous loss. PC rent with or without vitreous loss and zonular dialysis are largely associated with borderline outcome. Vitreous loss and tunnel complications are largely associated with poor visual outcome (Table 7).
Similarly, post-operative complications including Surgically Induced Astigmatism (SIA). Cystoid Macular Oedema, Retinal Detachment and Endophthalmitis were recorded (Table 8) and evaluated for their relation to postoperative visual outcome and intraoperative complications (Table 9 and 10).

\section{DISCUSSION}

Cataract blindness is the main target of National Program for Control of Blindness in India and most of the resources are diverted for the elimination of the same. A lot of emphasis is laid upon increasing the coverage of cataract surgery. It includes organization of eye camp surgeries by government and non-government organizations. Considering the immense load of cataract blindness and limited resources it is not unlikely that the qualitative aspect could sometimes be ignored. This is particularly true while considering the community at large. With increase in awareness of the quality of life in general and quality of eye care, in particular various reports have been published regarding the poor outcome of cataract surgery at the community level in India.

483 cases of clear corneal manual small incision cataract surgery were studied for visual outcome at tertiary care hospital. Follow-up of patients was done on $1^{\text {st }}, 4^{\text {th }}$ and $8^{\text {th }}$ week and those factors responsible for low visual outcome at $8^{\text {th }}$ week; were tried to be identified. As per Table 3, preoperative visual acuity of less than $3 / 60$ was seen in 479 $(58.13 \%)$ of cases. It can be explained by the fact that maximum patients visiting tertiary care hospital come from low socioeconomic strata who earn by daily wages. So, they tend to present themselves at the last moment when they cannot work anymore with their low vision. In the present study, only $22(4.55 \%)$ cases fit in the group having preoperative visual acuity $>6 / 60$. Yorston $\mathrm{D}$ et $\mathrm{al}^{1}$ in his study compared pre-operative visual acuity with that of a study in United Kingdom. In the latter group $30 \%$ of the eyes undergoing surgery had vision of $6 / 18$ or better, but in his study he reported only $0.5 \%$ of eyes operated had this level of visual acuity. Our study goes well with the study conducted by Yorston D. Majority of the patients in this study belonged to rural areas.

Out of 483 patients, 25 (5.18\%) patients were lost to follow-up. Table 5 shows that out of remaining 458 patients, 
396 (86.46\%) had good visual outcome. Yorston D in more than $80 \%$ cases, Gogate PM. ${ }^{2}$ in $89.8 \%$ and Oladigbolu KK. ${ }^{3}$ in 87.1\% patients. Our study corresponds well with other studies as well as fairly meets guidelines given by WHO. Data of all 62 patients with borderline and poor outcome was studied and according to Table 6, intraoperative complications 39 (8.51\%) were the major cause responsible for low visual outcome.

Yorston D et al in their study found that intraoperative complications occurred in $12.66 \%$ patients, Gogate PM et $\mathrm{al}^{2}$ in $8.1 \%$ and Oladigbolu $\mathrm{KK}_{\text {et }} \mathrm{al}^{3}$ reported $10.1 \%$ incidence of intraoperative complications. The rate of intraoperative complications of $9.8 \%$ in our study corresponds well with other studies and is also under the maximum limit of $10 \%$ as per guidelines given by WHO.

In Table 6, intraoperative complications are analysed and it is found that posterior capsule rent occurred in 16 (3.49\%) patients is the most common intraoperative complication followed by posterior capsule rent with vitreous loss 13 (2.83\%). Incidences of posterior capsule rent reported by various authors are: $3.77 \%$ by Gogate $\mathrm{PM}$ et $\mathrm{al}^{2}, 6.3 \%$ by Yorston D et al, $2.9 \%$ by Oladigbolu $\mathrm{KK}$ et $\mathrm{al}^{3}, 5.4 \%$ by Lumme $\mathrm{P}^{4}$ et al and $4.5 \%$ by Schroeder $\mathrm{B}^{5}$ et al. Incidences of posterior capsule rent with vitreous loss are $1.6 \%$ by Gogate PM et al and $5.1 \%$ by Yorston D et al. In our study, rate of both complications is well below the maximum limit of $5 \%$ as per guidelines given by WHO and corresponds well with other studies.

Zonular dialysis was seen in $7(1.52 \%)$ patients, while Tunnel complications occurred in 5 (1.1\%) patients; 2 cases had premature entry and 3 cases had irregular anteriorly displaced tunnel.

Iridodialysis was seen in $2(0.44 \%)$ cases, which were 1 clock hour in extent and did not have any significance in the final visual outcome. Descemet's detachment was seen in 1 $(0.22 \%)$ cases in the present study. Schroeder reported Descemet's detachment in $0.7 \%$ of cases.

Other early postoperative complications like striate keratopathy, iritis, hyphema and raised intraocular pressure were managed successfully and did not affect final visual outcome in any way and hence not discussed here.

It was observed that only those patients who had intraoperative complications suffered from postoperative complications including surgically induced astigmatism, Cystoid macular oedema, Retinal Detachment and Endophthalmitis.

Cases of tunnel complications and zonular dehiscence had high degrees of SIA ( $>2$ Dioptres) and only patients with vitreous loss with posterior capsular rent suffered from Retinal Detachment and Endophthalmitis.

All patients who had postoperative SIA and CME had borderline visual outcome and those who suffered RD or endophthalmitis had poor visual outcome.

Thus, it can be inferred that the most important measure for prevention of postoperative complications is to avoid intraoperative complications, especially tunnel complications and vitreous loss.

Limitation of this study is incomplete follow-up, i.e. less than $95 \%$ - which could easily give rise to large bias resulting in gross underestimates of poor outcome after surgery. Short duration of study is another limitation of this study.
This study shows that after good selection of patients, a clear corneal cataract surgery by skilled and experienced hands and with postoperative correction of refractive error; good visual outcome can be achieved in more than $85 \%$ patients at a setup like tertiary care hospital. It still falls short of guidelines of WHO which demands more than $90 \%$ patients with good visual outcome. In our setup, scope of improvement lies in reduction in incidence of intraoperative complication. Rather, a good management of complications with good quality of instruments and operating microscope, availability of modern enmities like vitrectomy machines, capsular tension rings can definitely improve visual outcome and will go a long way in improving both quality and quantity of surgery.

Despite what modern technology has done to advance the treatment of cataracts, the greatest challenge in our field continues to be large and increasing backlog of cataract blindness in developing countries. Manual Small Incision Clear Corneal Cataract Surgery is an upcoming surgical procedure for cataract surgery in developing countries like India. Visual outcome of cataract surgery at eye camps fairly meets the guidelines given by WHO. Intraoperative and postoperative complications followed by retained lens material are important causes of low visual outcome for these patients. This study shows that scope of improvement in visual outcome lies in reducing incidence of intraoperative and postoperative complications and management of them with good quality of instruments and modern techniques; the complications managed with standard surgical techniques are surely compatible with good visual outcome.

Prospective standardized monitoring of cataract surgical outcomes with regular analysis of the causes of poor outcome is an important tool, which individual ophthalmic surgical teams can use to improve the results of their cataract surgery. The emphasis should be on continuous internal audit over time in order to improve results, rather than on inappropriate comparison of results between canters or surgeons. Routine monitoring of visual outcome of cataract surgery at every hospital will go in a long way to improve both quantity and quality of surgery and thus reduce the substantial amount of burden of blindness on our country.

\section{REFERENCES}

1. Yorston D, Gichuhi S, Wood M, et al. Does prospective monitoring improve cataract surgery outcomes in Africa? Br J Ophthalmol 2002;86(5):543-7.

2. Gogate PM, Deshpande M, Wormald RP, et al. Extracapsular cataract surgery compared with manual small incision cataract surgery in community eye care setting in western India: a randomised controlled trial. Br J Ophthalmol 2003;87(6):667-72.

3. Oladigbolu KK, Rafindadi AL, Mahmud-Ajeigbe AF, et al. Outcome of cataract surgery in rural areas of Kaduna State, Nigeria. Ann Afr Med 2014;13(1):25-9.

4. Lumme P, Laatikainen LT. Risk factors for intraoperative and early postoperative complications in extracapsular cataract surgery. Eur J Ophthalmol 1994;4(3):151-8.

5. Schroeder B. Sutureless cataract extraction: complications, management and learning curves. Community Eye Health 2003;16(48):58-60. 